\title{
Power Quality Analysis and Enhancement of Grid Connected Solar Energy System
}

\author{
Kokilavani Thangaraj1, Selvakumar Gopalasamy ${ }^{2}$ \\ ${ }^{1}$ Anna University, Chennai, India \\ ${ }^{2}$ Department of Electrical Sciences, Muthaymmal Engineering College, Namakkal, India \\ Email: kokime.t@gmail.com,ngselva_kumar@yahoo.com
}

Received 7 April 2016; accepted 1 May 2016; published 28 June 2016

Copyright (C) 2016 by authors and Scientific Research Publishing Inc.

This work is licensed under the Creative Commons Attribution International License (CC BY). http://creativecommons.org/licenses/by/4.0/

c) (i) Open Access

\begin{abstract}
In recent years, renewable energy resources are utilized to meet the growing energy demand. The integration of renewable energy resources with the grid incorporates power electronic converters for conversion of energy. These power electronic converters introduce power quality issues such as a harmonics, voltage regulation etc. Hence, to improve the power quality issues, this work proposes a new control strategy for a grid interconnected solar system. In this proposed work, a maximum power point tracking (MPPT) scheme has been used to obtain maximum power from the solar system and DC/DC converter is implemented to maintain a constant DC voltage. An active filtering method is utilized to improve the power quality of the grid connected solar system. The proposed system is validated through dynamic simulation using MATLAB/Simulink Power system toolbox and results are delivered to validate the effectiveness of the work.
\end{abstract}

\section{Keywords}

Power Quality, Active Power Filter, Fuzzy Controller, Harmonics Compensation

\section{Introduction}

The increase in industrialization leads to energy demand. Most of the energy demand is supplied by the fossil fuels. However, increase in air pollution, diminishing fossil fuels and their increasing cost have made it necessary to gaze towards renewable energy sources as a future energy solution. Among these Renewable Energy Sources (RES), solar power systems are the affable solution for electrification. As the solar energy is available in nature and due to its inexhaustible availability, it has become one of the most promising renewable energies. Hence, PV system has been increasingly used in medium sized grid. The interconnection of PV systems with Grid is accomplished with the inverter, which in turn converts DC power generated from PV modules to AC 
power. This penetration of power electronic converters may create a hazard to network in terms of power quality problems such as harmonics. This harmonics may lead to malfunctioning of protective relays and other control unit. Hence the harmonics has to be reduced. Shunt active power filters (SAPF) have been recognized as most effective solution for harmonic compensation [1]-[5]. But the implementation of SAPF leads to an additional cost. Hence the feature of SAPF is incorporated with the inverter which interfaces RES with the grid, without any additional cost [6]-[10]. While the SAPF function is accompanied with the inverter. Controller plays the vital role in the design of the active power filter. Recently, fuzzy control has generated a great interest in some power electronics field and has been applied to many practical industrial applications. Fuzzy control methods have also been applied to APF [12] [13]. The fuzzy control has advantages over the PI controller such as: it does not need an accurate mathematical model; it can handle non linearity and it is more robust than the PI controller; it can work with imprecise inputs, etc. Hence, this work validates an enhanced control strategy to improve the power quality of the grid interconnected solar system in terms of harmonic reduction and reactive power compensation.

\section{Proposed Methodology}

Thus the Configurations of a photovoltaic interactive shunt active power filter system is shown in Figure 1. Solar energy is converted into electricity through PV array. The power from the photovoltaic system varies according to the climatic conditions. Hence, to obtain a maximum power from PV array, it is coupled with a Maximum Power Point Tracker (MPPT). As the photovoltaic energy sources generate power at variable low dc voltage, it requires power conditioning before connecting on DC-link. For this purpose, DC-DC converter is used. The output obtained from the DC-DC converter is coupled to DC-link capacitor which in turn connected to grid through inverter.

The voltage source inverter transfer active power from a renewable energy source and also operates as a SAPF to compensate the current harmonics. When sunlight is absent, the PV system is disconnected from the grid through the dc capacitor [14].

\subsection{Design of Solar System}

PV cells grouped in large unit forms a PV module and are connected in series-parallel configuration to form PVrray. The output of the PV module is connected to the MPPT which maximizes the power produced by the panels. Various MPPT algorithms are available to improve the performance of PV system. Among these, Perturb-Observe (PO) is implemented here. Thus, a maximum power point tracker achieves maximum power from the solar PV module. A non-isolated DC-DC converter is implemented for conversion of this maximum power to the grid. This converter acts as an interface between the SAPF and the module. The MPPT controller controls

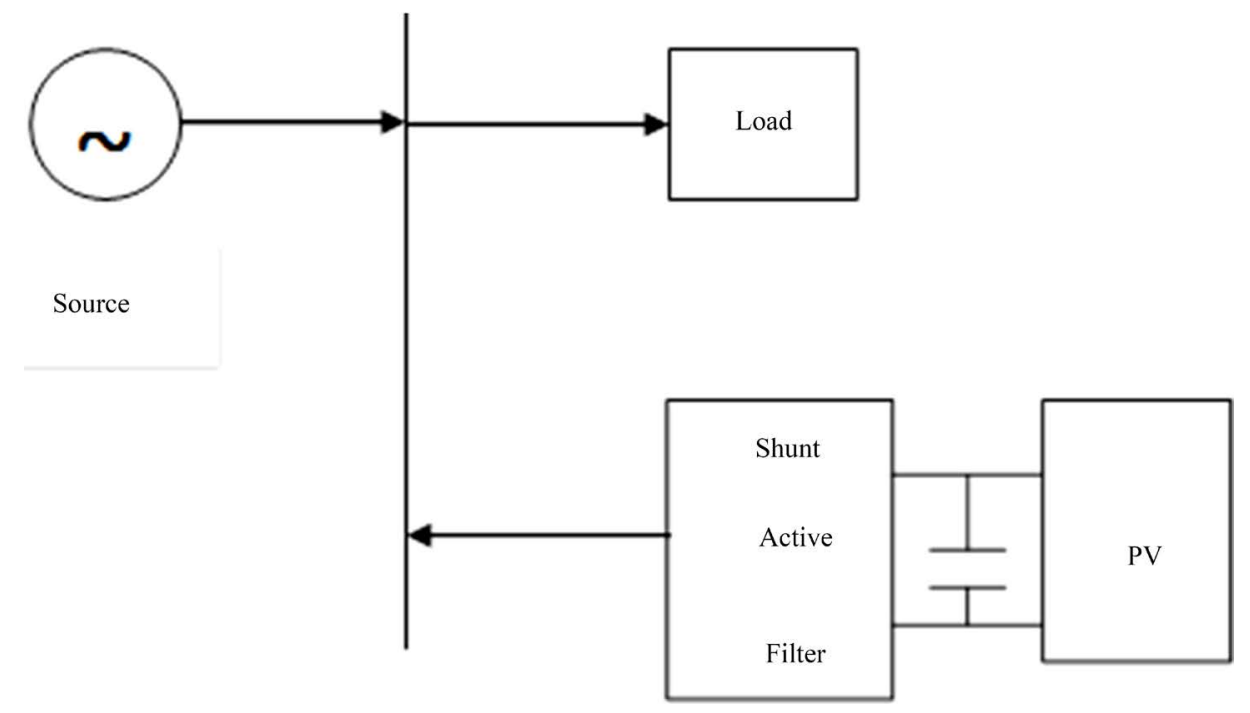

Figure 1. Configurations of a photovoltaic interactive shunt active power filter system. 
the output voltage of the DC-DC converter by regulating the PWM signals applied to the switch of the converter unit. The output from the DC-DC converter is connected to dc link capacitor which in turn connected to grid through inverter.

\subsection{DC-Link Voltage and Power Control Operation}

The function of the SAPF is to compensate current harmonics by injecting equal-but-opposite harmonic compensating currents into the grid. In order to generate compensating current, it is necessary to estimate the reference current [11]. Synchronous Reference Frame Theory is used to calculate the reference current. The peak value of the reference grid current is determined by the DC voltage regulator.

\subsection{Synchronous Reference Frame Theory}

The output of the d-q transformation shown in Figure 2 depends upon the PLL circuit PLL circuit and the PLL circuit. The PLL delivers $\cos \theta$ and $\sin \theta$ for synchronization [15]. If AC source currents are $i_{s a}, i_{s b}, i_{s c}$, load currents are $i_{L a}, i_{L b}, i_{L c}$ and the filter compensating currents are $i_{f a}, i_{f b}, i_{f c}$ then the load currents are converted into d-q reference frame is shown in the Equation(1).

$$
\left[\begin{array}{l}
i_{d} \\
i_{q}
\end{array}\right]=\sqrt{\frac{2}{3}}\left[\begin{array}{ccc}
\cos \theta & \cos \left(\theta-\frac{2 \pi}{3}\right) & \cos \left(\theta+\frac{2 \pi}{3}\right) \\
\sin \theta & -\sin \left(\theta-\frac{2 \pi}{3}\right) & -\sin \left(\theta+\frac{2 \pi}{3}\right)
\end{array}\right]\left[\begin{array}{l}
i_{L a} \\
i_{L b} \\
i_{L c}
\end{array}\right]
$$

These currents are composed of DC component and harmonic component are shown in Equation (2).

$$
I_{d}=I_{d d c}+I_{d h}, I_{q}=I_{d c}+I_{q h}
$$

These d-q currents are passed through LPF which allows only the fundamental frequency component thereby eliminating harmonic component of the load current. Thus the harmonic component obtained using LPF is shown in Equation (3).

$$
I_{d h}=I_{L}-\operatorname{LPF}\left(I_{d}\right), I_{q h}=I_{L}-\operatorname{LPF}\left(I_{q}\right)
$$

The LPF is designed using second order Butterworth filter. The output of the voltage controller is subtracted from harmonic component of direct axis in order to eliminate the steady state error. The inverse transformation from d-q to a-b-c is achieved through Equation (4)

$$
\left[\begin{array}{l}
i_{c a}^{*} \\
i_{c b}^{*} \\
i_{c c}^{*}
\end{array}\right]=\sqrt{\frac{2}{3}}\left[\begin{array}{cc}
\cos \theta & \sin \theta \\
\cos \left(\theta-\frac{2 \pi}{3}\right) & -\sin \left(\theta-\frac{2 \pi}{3}\right) \\
\cos \left(\theta+\frac{2 \pi}{3}\right) & -\sin \left(\theta+\frac{2 \pi}{3}\right)
\end{array}\right]\left[\begin{array}{l}
i_{d h} \\
i_{q h}
\end{array}\right]
$$

Thus, the AC components of $\mathrm{d}$ axis and $\mathrm{q}$ axis are used for harmonics elimination and reactive power compensation.

\subsection{Design of Fuzzy Controller}

A fuzzy controller is designed to produce the peak value of the grid current (Benaissa et al. 2012). The fuzzy logic controller is characterized as follows

> Seven fuzzy sets (NB, NM, NS, ZE, PS, PM, PB) for each input and output variables.

$>$ Triangular membership function is used because of its simplicity

$>$ Implication using Mamdani-type min-operator

Defuzzification using the centroid method.

The conversion of fuzzy values is shown in Figures 3(a)-(c) by the membership functions. 


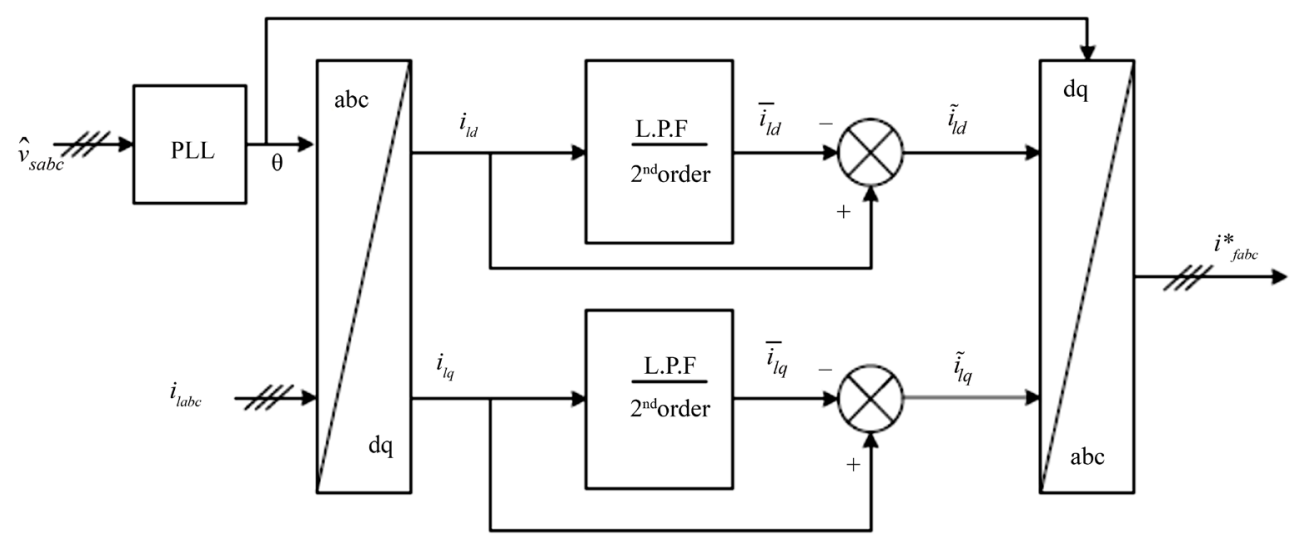

Figure 2. Block diagram of synchronous reference frame theory.

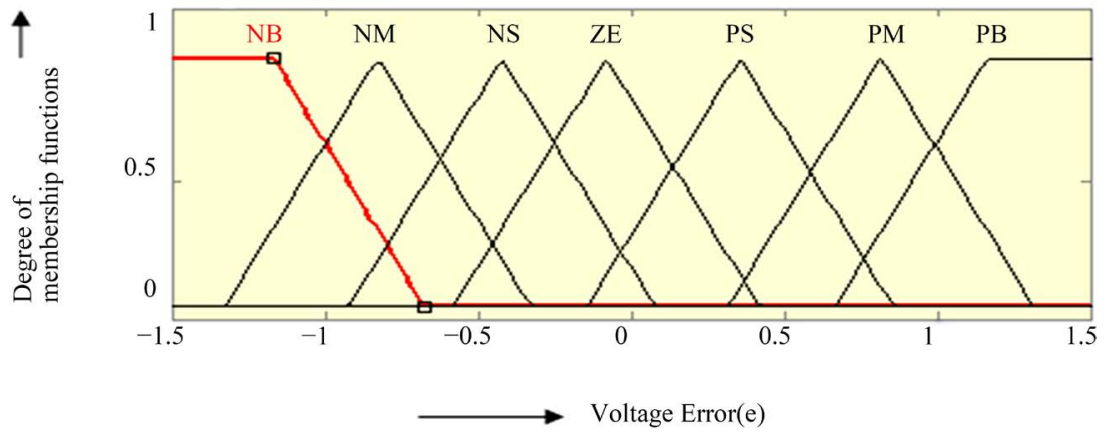

(a)

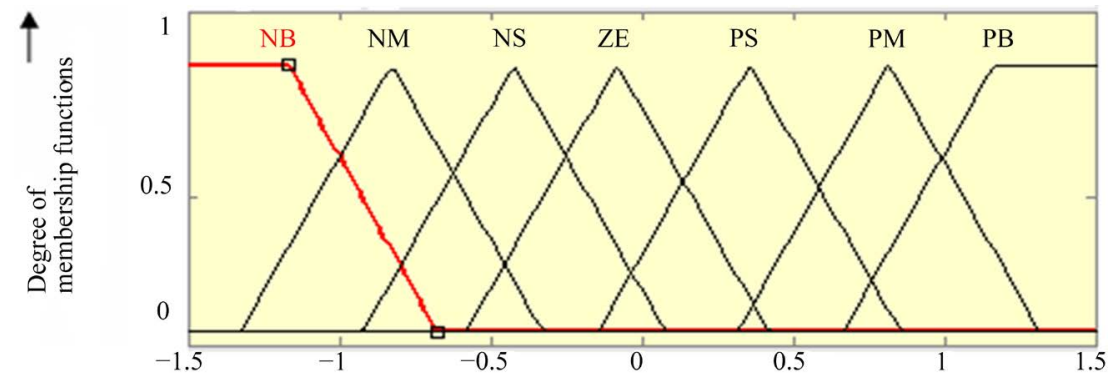

MFs for $\Delta \mathrm{e}$

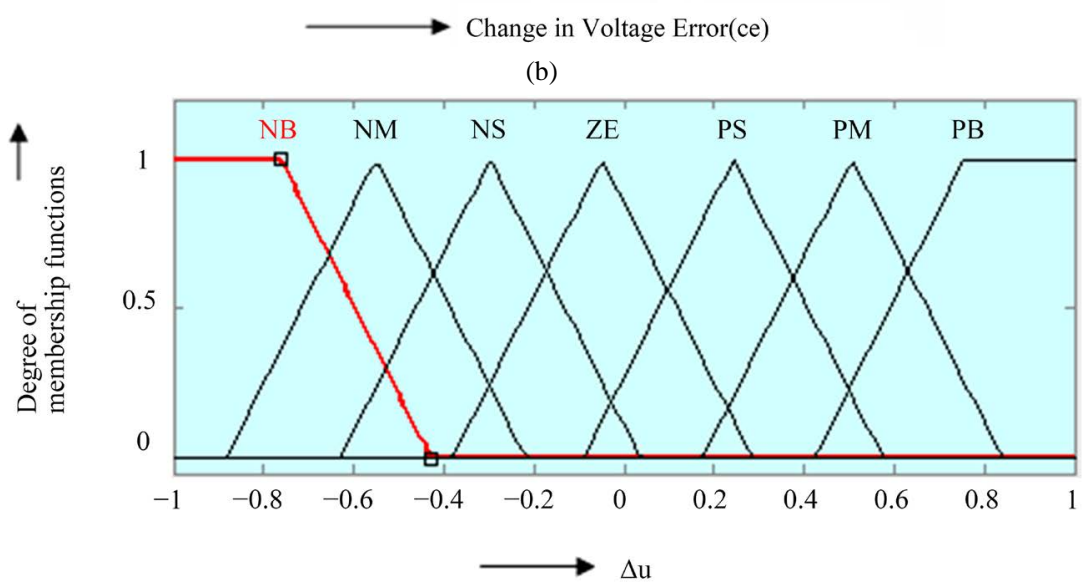

(c)

Figure 3. (a) Membership functions for e; (b) Membership functions for $\Delta \mathrm{e}$; (c) Membership functions for $\Delta \mathrm{u}$. 
The Rule base stores the linguistic (fuzzy) control rules required by the rule evaluator (decision making logic), the 49-rules used are presented in Table 1.

This estimated magnitude of peak-current multiplied with an output of unit sine vector determines the reference currents. The reference currents are compared with actual source currents to generate VSI-switching pulses using PWM-current controller. This controller handles nonlinearity and it is more robust. It facilitates reduction of ripples in dc-link capacitor of the PWM-inverter.

\subsection{Hysteresis Controller}

For the PWM-voltage source inverter; hysteresis current controllers are configured for each phase. Each current controller generates the switching signal of the three $(\mathrm{a}, \mathrm{b}, \mathrm{c})$ phases. If the input current is positive and error current $\mathrm{e}(\mathrm{t})$ is between the desired reference current iref(t), the load current iload(t) exceeds the upper hysteresis band limit (+h) and hence the upper switch of the inverter arm is in OFF state and the lower switch is in ON state. Thus the current starts decreasing. Similarly, if the error current e (t) crosses the hysteresis bands (-h) lower limit, the lower switch in the inverter arm turns OFF and the upper switch switches ON. Now, the current gets back into the hysteresis band and the cycle goes on repeating.

\section{Results and Discussion}

By using MATLAB/Simulink, the simulation study is carried out to verify the proposed control approach to achieve multi-objectives for grid interfaced solar system.

For simulation, the system parameter values used are given in Table 2.

To compensate the current harmonics, active filter connected at the PCC to inject anti-harmonics and make the supply current sinusoidal. The SAPF consists of VSI inverter, dc-link capacitor, reference current extraction controller and switching pulse generator. The reference current extraction process is developed from synchronous reference frame theory for extracting the reference currents from the distorted currents. The fuzzy estimates the magnitude of peak reference current Imax by controlling the dc-link capacitor. This peak amplitude is multiplied with the unit current templates to generate the required reference current. The reference current is compared with actual current to generate the gate control switching pulses using pulse width modulation.

Primarily, the inverter is not connected with the network. Figure 4 shows the grid current profile before compensation.

This source current is polluted with the harmonic distortion. When the inverter is coupled to the network, it injects the current. As a result of this, the source current changes from unbalanced to balanced sinusoidal current. The voltage and current waveform of a source after compensation was shown in Figure 5.

Table 1. Rule base of fuzzy controller.

\begin{tabular}{cccccccc}
\hline$\Delta \mathrm{e} / \mathrm{e}$ & NB & NM & NS & ZE & PS & PM & PB \\
\hline NB & NB & NB & NB & NM & NM & NS & ZE \\
NM & NB & NB & NM & NS & NS & ZE & PS \\
NS & NB & NM & NS & NS & ZE & PS & PM \\
ZE & NM & NS & NS & ZE & PS & PS & PM \\
PS & NM & NS & ZE & PS & PS & PM & PB \\
PM & NS & ZE & PS & PS & PM & PB & PB \\
PB & ZE & PS & PM & PM & PB & PB & PB \\
\hline
\end{tabular}

Table 2. List of parameters used in simulation.

\begin{tabular}{cc}
\hline Source Voltage $\left(\mathrm{V}_{\mathrm{s}}\right)$ & $360 \mathrm{~V}(\mathrm{rms}), 50 \mathrm{~Hz}$ \\
Dc-link capacitance $\left(\mathrm{C}_{\mathrm{dc}}\right)$ & $2200 \mu \mathrm{F}$ \\
Diode Bridge Rectifier with RL Load & $50 \Omega$ and $20 \mathrm{mH}$. \\
\hline
\end{tabular}




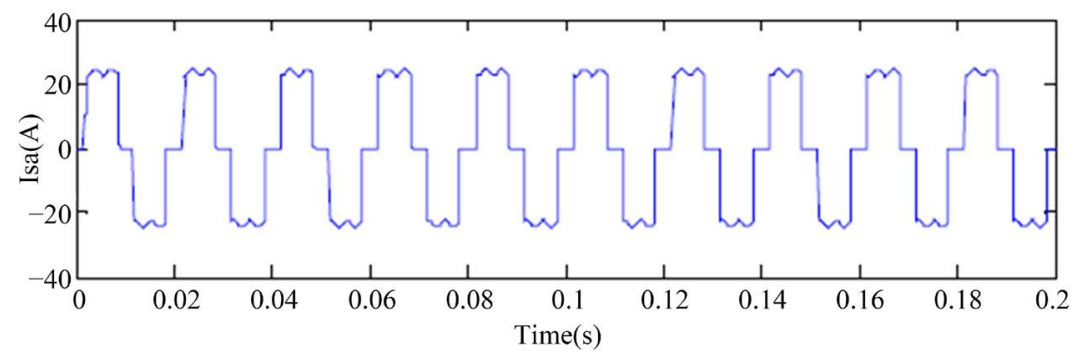

Figure 4. Source current for nonlinear load before compensation.

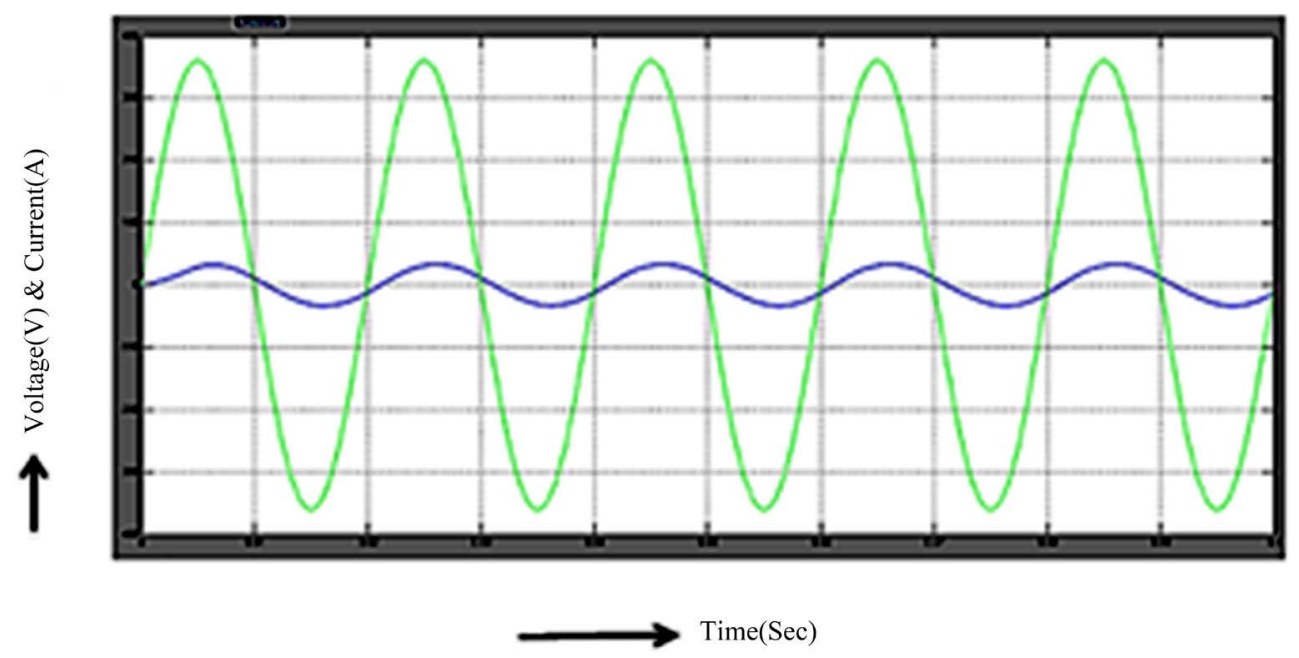

Figure 5. Voltage and current of source after compensation.

From the figure, it is observed that this system performs both harmonics and reactive power compensation simultaneously.

\section{System Analysis}

The efficiency of active filter is evaluated in terms of power factor, order of harmonics and real and reactive power compensation.

\subsection{THD Analysis}

Figure 6 illustrates plots of the order of harmonics versus magnitude in source current with filter. With filter, the order of harmonics is reduced to less than $5 \%$. The FFT is used to measure the order of harmonics.

From the Figure, it is observed that the total harmonic distortion (THD) of the source current is upgraded after compensation and it is within the acceptable limit of IEEE 519 standard for current distortions in distribution system. Thus from the simulation results, it is obvious that this method can be used for current harmonics reduction and reactive power compensation along with inoculation of power from solar system.

\subsection{Real and Reactive Power}

When the inverter is connected to the network, it injects the current whish in turn cancels the harmonic current. Thus, the source current becomes balanced sinusoidal current. The current and voltage waveform of a source after compensation is shown in Figure 7. From the figure, it is perceived that this system permits both harmonics and reactive power compensation simultaneously.

Thus the performance analysis of SAPF measured in terms of order of harmonic and power factor are presented in Table 3. 


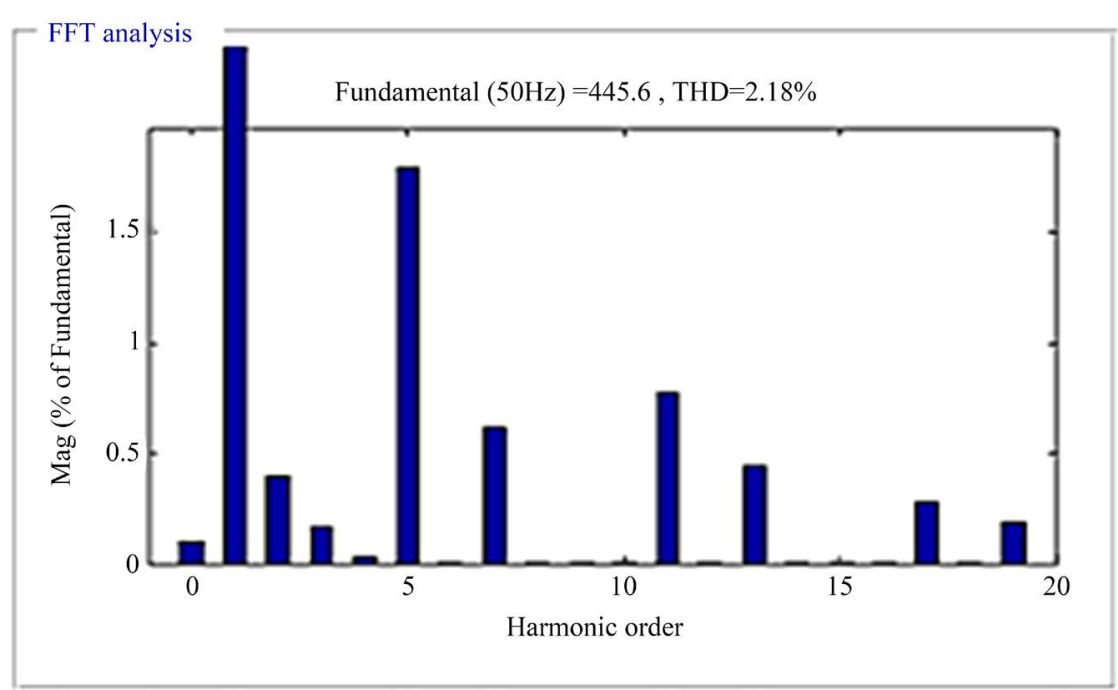

Figure 6. Harmonic spectrum of source current with SAF.

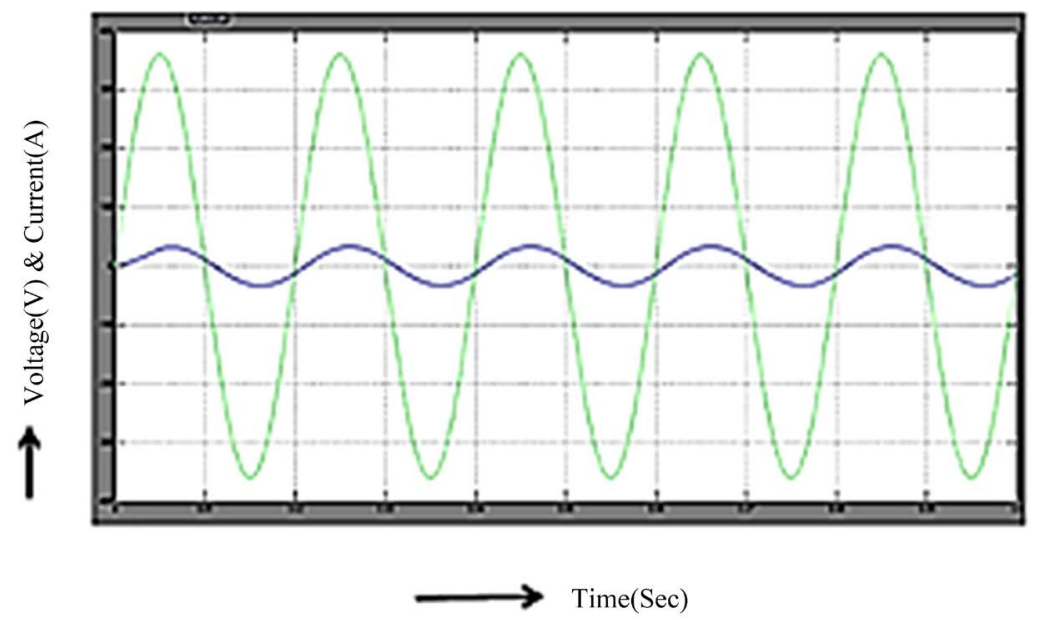

Figure 7. Voltage and current of source after compensation.

Table 3. Performance analysis of SAPF.

\begin{tabular}{|c|c|c|c|c|}
\hline Load & Condition & THD (\%) & P\&Q Power & Power Factor \\
\hline \multirow{2}{*}{ Diode rectifier with RL load } & Without SAPF & 22.04 & $\begin{aligned} \mathrm{P} & =8.99 \mathrm{~kW} \\
\mathrm{Q} & =239 \mathrm{VAR}\end{aligned}$ & 0.9547 \\
\hline & With SAPF & 2.47 & $\begin{array}{l}\mathrm{P}=9.29 \mathrm{~kW} \\
\mathrm{Q}=98 \mathrm{VAR}\end{array}$ & 0.9997 \\
\hline
\end{tabular}

\section{Conclusion}

This work has presented a novel control of an existing grid interfacing inverter to improve the quality of power at PCC. It has been proved that the grid-interfacing inverter can be effectively utilized for power conditioning without affecting its normal operation of real power transfer. This approach eliminates the need for additional power conditioning equipment to improve the quality of power. Extensive MATLAB/Simulink simulation results have validated the proposed approach and have shown that the grid-interfacing inverter can be utilized as a multi-function device.

\section{References}

[1] Akagi, H. (2006) Modern Active Filters and Traditional Passive Filters. Bulletin of the Polish Academy of Sciences 
Technical Sciences, 54, 255-269.

[2] Kazem, H.A. (2013) Harmonic Mitigation Techniques Applied to Power Distribution Networks. Advances in Power Electronics. http://dx.doi.org/10.1155/2013/591680

[3] Ravindra, S., Veera Reddy, V.C., Sivanagaraju, S. and Gireesh Kumar, D. (2012) Design of Shunt Active Power Filter to Eliminate the Harmonic Currents and to Compensate the Reactive Power under Distorted and or Imbalanced Source Voltages in Steady State. International Journal of Engineering Trends and Technology, 3, 1-6.

[4] Kumar, A. and Singh, J. (2013 Harmonic Mitigation and Power Quality Improvement Using Shunt Active Power Filter. International Journal of Electrical, Electronics and Mechanical Control, 2, 13 p.

[5] Gligor, A. (2009) Design and Simulation of a Shunt Active Filter in Application for Control of Harmonic Levels. Acta Universitatis Sapientiae, Electrical and Mechanical Engineering, 53-63.

[6] Khazaie, J., Nazarpour, D., Farsadi, M., Khalilian, M. and Badkubi, S. (2012) Shunt Hybrid Active Power Filter to Alleviate the Harmonics of VSC-HVDC in Off-Shore Wind Farms. International Journal on Technical and Physical Problems of Engineering (IJTPE), 4, 162-169.

[7] Singh, M., Khadkikar, V., Chandra, A. and Varma, R.K. (2011) Grid Interconnection of Renewable Energy Sources at the Distribution Level With Power-Quality Improvement Features. IEEE Transactions on Power Delivery, 26, 307315.

[8] MohanaPriyaa, N. and Jayashree, J. (2013) Mitigation of Power Quality Features With the Renewable Energy Sources at the Distribution Level. International Journal of Innovative Research \& Development, 2, 643-652.

[9] Jahromi, S.N. and Ghandehari, R. (2012) A Novel and Fast Technique for Harmonic Reduction Based on Wavelet Analysis and Active Filter in Wind Farms. IRACST_Engineering Science and Technology, An International Journal (ESTIJ), 2, 825-830.

[10] Abniki, H., Bashooki, M. and EhsanKargahi, M. (2013) A Wavelet Based Technique for DFIG Harmonic Reduction in Frequency Domain Based Model of Power System Using Active Filter. International Journal of Energy Engineering, 3, 209-216.

[11] Shyamsundar, J., Gupta, R.K. and ChittiBabu, B. (2013) Comparative Study between Different Control Strategies for Shunt Active Power Filter. 1st National Conference on Power Electronics Systems \& Applications, PESA 2013.

[12] Agrawal, S. and Bhuria, V. (2013) Shunt Active Power Filter for Harmonic Mitigation by Using Fuzzy Logic Controller. International Journal of Advanced Research in Computer Engineering \& Technology (IJARCET), 2, Issue 6.

[13] Singh, R., Asheesh, K. and Rakesh, K. (2011) Approximated Simplest Fuzzy Logic Controlled Shunt Active Power Filter for Current Harmonic Mitigation. International Journal of Fuzzy System Applications, 1, 36. http://dx.doi.org/10.4018/ijfsa.2011100102

[14] Belaidi, R., Haddouche, A., Fathi, M., MghezziLarafi, M. and Chikouche, A. (2011) Improvement of the Electrical Energy Quality Using a Shunt Active Filter Supplied by a Photovoltaic Generator. Energy Procedia, 6, 522-530. http://dx.doi.org/10.1016/j.egypro.2011.05.060

[15] Da Silva, S.A.O., Neto, A.F., Cervantes, S.G.S., Goedtel, A. and Nascimento, C.F. (2010) Synchronous Reference Frame Based Controllers Applied to Shunt Active Power Filters in Three-Phase Four-Wire Systems. Proceedings of the IEEE International Conference on Industrial Technology (ICIT), Vi a del Mar, 14-17 March 2010, 832-837. http://dx.doi.org/10.1109/icit.2010.5472605

\section{Submit or recommend next manuscript to SCIRP and we will provide best service for you:}

Accepting pre-submission inquiries through Email, Facebook, Linkedin, Twitter, etc

A wide selection of journals (inclusive of 9 subjects, more than 200 journals)

Providing a 24-hour high-quality service

User-friendly online submission system

Fair and swift peer-review system

Efficient typesetting and proofreading procedure

Display of the result of downloads and visits, as well as the number of cited articles

Maximum dissemination of your research work

Submit your manuscript at: http://papersubmission.scirp.org/ 